\title{
Control Method of Thermo-Oxidative Stability Factors of Synthetic Motor Oil
}

\author{
Lysyannikova Natalia Nikolaevna $^{(\bowtie)}$, Kravcova Ekaterina Gennadievna ${ }^{1}$, Kovaleva Maria Alexandrovna $^{1}$ \\ ${ }^{1}$ Siberian Federal University, Institute of Oil and Gas, 82/6 Svobodny Ave, Krasnoyarsk, 660041, Russian Federation \\ Corresponding author: E-mail: Nataly.nm@mail.ru
}

\begin{abstract}
The article presents the research results of effect of temperature on a number of thermo-oxidative stability factors, including optical density, volatility, thermo-oxidative stability index and potential resource. Method of research of lubricating oils for thermal-oxidative stability is described and includes the application of testing devices and control, such as a device for thermostating of the oils, photometer for direct electrophoretic oxidized oils and electronic scales. Dependences of optical density, potential resource, volatility, thermooxidative stability factors with time and testing temperature of synthetic motor oil, on the basis of which new factors of thermo-oxidative stability were proposed and including the temperatures of the onset of oxidation, volatility and temperature transformations in oil, and the critical temperatures of these processes. The article proposes a grapho-analytical model for definition of thermo-oxidative stability factors at all temperatures without research based on oil testing under two temperatures, which possible to reduce the labour inputs of the research more than two fold. The proposed control method of thermo-oxidative stability factors allows us to expand information on the quality of lubricants by determining the onset temperatures of oxidation, evaporation and temperature conversions in oil, as well as critical temperatures of this processes. It also allows to improve the classification system by the groups of operational properties.
\end{abstract}

Keywords Optical density, Volatility, Thermo-oxidative stability, Grapho-analytical model, Potential resource, Critical temperatures.

\section{Introduction}

Thermo-oxidative stability is an operational factor, which determines ageing resistance of lubricating oils. There are many control methods for this factor [1-18], part of which are standardized, however consumers are not provided with the full information about resilience of lubricating oils to temperature effects. For that reason, finding new methods of control and gauge for thermo-oxidative stability is a crucial task, which expands information about quality of oils and their informed choice for differently loaded equipment.

The purpose of researches to develop a control method for thermo-oxidative stability factors, which will allow expanding information about resilience of lubricating oils to the temperature effects in the wide range of temperature tests.

\section{Methodology}

Research method involved the use of the following test and control instruments: oil thermostatting device, a photometer for direct photometry of oxidized oils at a thickness of a photometric layer of $2 \mathrm{~mm}$ and electronic scales. The technical characteristics of the devices are given in the monograph [19-21].

Multigradesynthetic oils ALPHA'S 5W-30 SN/GF and LUKoil Luxe 5W-30 SL/CF were chosen for the research.

According to the research method, a sample of oil with a mass of $100 \pm 0.1 \mathrm{~g}$ was poured into a glass beaker of the thermostating device at atmospheric pressure while stirring with a glass stirrer with a rotation speed of 300 $\mathrm{rpm}$. The temperature of thermostating was set discrete and was maintained automatically with an accuracy of \pm $2{ }^{\circ} \mathrm{C}$. The duration of the test was determined by the time when the optical density of the oxidized oil reached the value of 0.5 to 0.6 units. Each 8 -hours of test, a glass beaker with an oxidized oil sample was weighed, the mass 
of the evaporated oil was determined, part of the sample $(2$ g.) was selected for direct photometry and determination of the optical density $D$.

$$
D=\log 300 / P
$$

where 300 - photometer readings when cuvette is devoid of fuel, uA; and $P$-photometer readings when cuvette is filled with oil, $\mathrm{uA}$;

Thermo-oxidative stability of synthetic oil was estimated from change in optical density D, volatility $\mathrm{G}$ and the coefficient of thermo-oxidative stability $P_{t o s}$

$$
P_{\text {tos }}=D+K_{G}
$$

where $\mathrm{K}_{\mathrm{G}}-$ volatility index

$$
K_{G}=m / M
$$

where $\mathrm{m}$ and $\mathrm{M}$ are the mass of evaporated oil during time $\mathrm{t}$, and the mass of oil before the tests, $\mathrm{g}$.

Thermo-oxidative stability coefficient $P_{t o s}$ takes into account effect of temperature on the change in optical density and evaporation, so it allows us to compare various oils according to this index.

\section{The results of research}

Fig. 1 shows variation of optical density with time and testing temperature of ALPHA'S 5W-30 SN/GF synthetic motor oil. It was found that as the temperature of the test was lowered from $190{ }^{\circ} \mathrm{C}$ to $160{ }^{\circ} \mathrm{C}$, the oxidation time to the optical density $D=0.2$ increased from 23 hours to 157 hours, i.e. increased by 6.83 times.

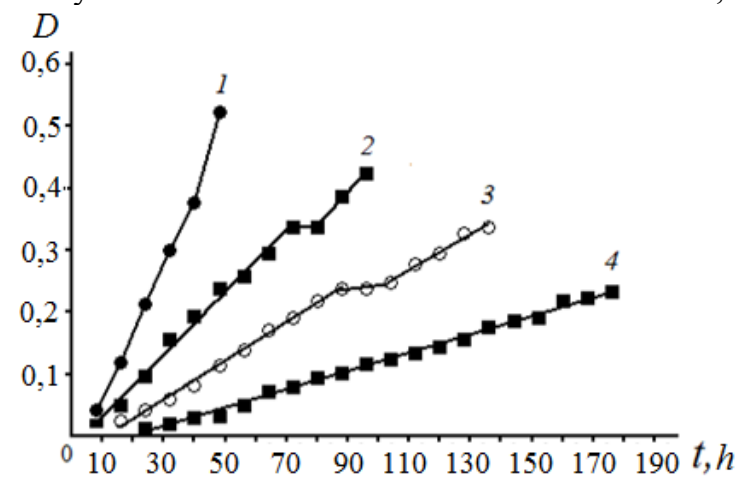

Fig. 1.Dependenceof optical density on time and testing temperature of ALPHA'S $5 \mathrm{~W}-30 \mathrm{SN} / \mathrm{GF}$ synthetic motor oil: $1-190{ }^{\circ} \mathrm{C} ; 2-180{ }^{\circ} \mathrm{C} ; 3-170{ }^{\circ} \mathrm{C} ; 4-160{ }^{\circ} \mathrm{C}$

Using dependence (Fig. 1), it is possible to determine potential resource $P$ of the oil under study at each temperature (Fig. 2a). These dependences are described by a polynomial of the second degree and regression equations for oils have the following form

$$
\begin{array}{ll}
\text { ALPHA'S 5W-30 SN/GF } & P=0.1975 T^{2}-75.735 T+7294.25 \\
\text { LUKoil Luxe 5W-30 SL/CF } & P=0.275 T^{2}-105.35 T+10113
\end{array}
$$

Indexes of correlation are 0.998 and 1.

According to data in Fig. 2a, potential resource of LUKoil Luxe 5W-30 SL/CF synthetic oil exceeds ALPHA'S 5W-30 SN/GF potential resource at temperatures below $175^{\circ} \mathrm{C}$.

One of the important thermo-oxidative stability factors is the onset temperature of oxidation processes, which is determined by the dependence of the optical density on the test temperature during 24 hours (Fig. 2b). These dependences are described by a polynomial of the second degree and regression equations for oils have the following form 


$$
\begin{array}{ll}
\text { ALPHA'S 5W-30 SN/GF } & D=\left(2.1 \times 10^{-4}\right) T^{2}-0.06696 T+5.35 \\
\text { LUKoil Luxe 5W-30 SL/CF } & D=\left(9 \times 10^{4}\right) T^{2}-31 T+26.71
\end{array}
$$

Indexes of correlation are 0.997 and 1.
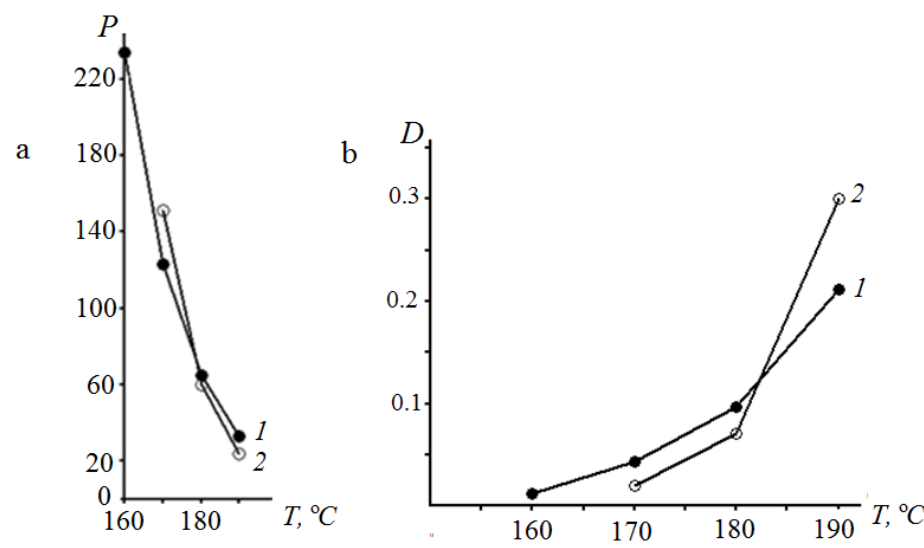

Fig. 2. (a) Dependence of synthetic motor oils potential resource on testing temperature: 1 -ALPHA'S 5W-30 SN/GF; 2 - LUKoil Luxe 5W-30 SL/CF (optical density D=0.3); (b) Dependence of the optical density on the testing temperature of synthetic motor oils: 1 - ALPHA’S 5W-30 SN/GF; 2 - LUKoil Luxe 5W-30 SL/CF (testing time - 24 hours)

Derivatives of equations 7 and 8 determine the average rates of change in optical density with testing temperature. If we equate them to zero, it is possible to determine the onset temperatures of oxidation processes. The results are $159.4^{\circ} \mathrm{C}$ for ALPHA'S 5W-30 SN/GF and $172.2^{\circ} \mathrm{C}$ for LUKoilLuxe $5 \mathrm{~W}-30 \mathrm{SL} / \mathrm{CF}$.

Another important thermo-oxidative stability factor is critical operability temperature of oils under study, which is determined by the time of optical density reaching the value of $D=0.05$ (Fig. 3).

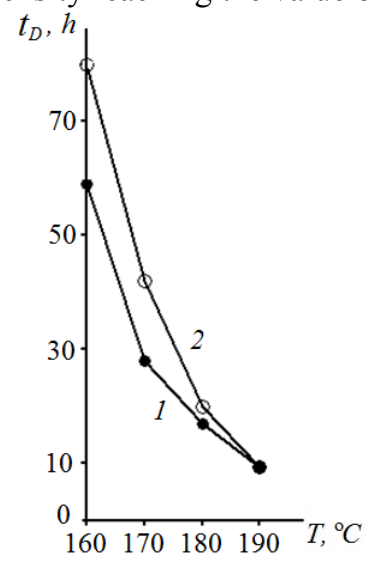

Fig. 3.Dependenceof time by which optical density reaches the value of $D=0.05$ on testing temperature of synthetic motor oils: 1 - ALPHA’S 5W-30 SN/GF; 2 - LUKoil Luxe 5W-30 SL/CF

These dependences are described by a polynomial of the second degree and regression equations for oils have the following form

$$
\begin{array}{ll}
\text { ALPHA'S 5W-30 SN/GF } & t_{D}=0.05875 T^{2}-22.157 T+2099.3 \\
\text { LUKoil Luxe 5W-30 SL/CF } & t_{D}=0.06875 T^{2}-26.397 T+2543.3
\end{array}
$$

Indexes of correlation are 0.99 and 0.99 .

Derivatives of equations 9 and 10 determine the rates of oxidation at each temperature. If we equate them to zero, it is possible to determine the critical temperature of oils under study. The results are $188.5^{\circ} \mathrm{C}$ for ALPHA'S $5 \mathrm{~W}-30 \mathrm{SN} / \mathrm{GF}$ and $192^{\circ} \mathrm{C}$ for LUKoilLuxe $5 \mathrm{~W}-30 \mathrm{SL} / \mathrm{CF}$.

Fig. 4a demonstrates dependence of volatility on time and testing temperature of ALPHA'S 5W-30 SN/GF synthetic motor oil. It shows that with decreasing test temperature, the rate of evaporation processes decreases. 
Seven grams of oil evaporate in 29 hours at a temperature of $190^{\circ} \mathrm{C}$, and in 160 hours at $160{ }^{\circ} \mathrm{C}$, i.e. with a decrease in temperature from 190 to $160{ }^{\circ} \mathrm{C}$, evaporation time of seven grams increases by 5.52 times.

Fig. $4 \mathrm{~b}$ shows dependence of synthetic motor oil volatility on testing temperature after eight hours of testing. These dependence are used to determine onset temperatures of evaporation processes. These dependences are described by a polynomial of the second degree, and regression equations for oils have the following form

$$
\begin{array}{ll}
\text { ALPHA'S 5W-30 SN/GF } & G=\left(5 \times 10^{-4}\right) T^{2}-0.125 T+8.1 \\
\text { LUKoil Luxe 5W-30 SL/CF } & G=\left(5 \times 10^{-4}\right) T^{2}-0.085 T+0.8
\end{array}
$$

Indexes of correlation are 0.999 and 1.

Derivatives of equations 11 and 12 determine the average rates of evaporation. If we equate them to zero, it is possible to determine the onset temperatures of oxidation processes for oils under study. The results are $125^{\circ} \mathrm{C}$ for ALPHA'S 5W-30 SN/GF and $160^{\circ} \mathrm{C}$ for LUKoil Luxe 5W-30 SL/CF.
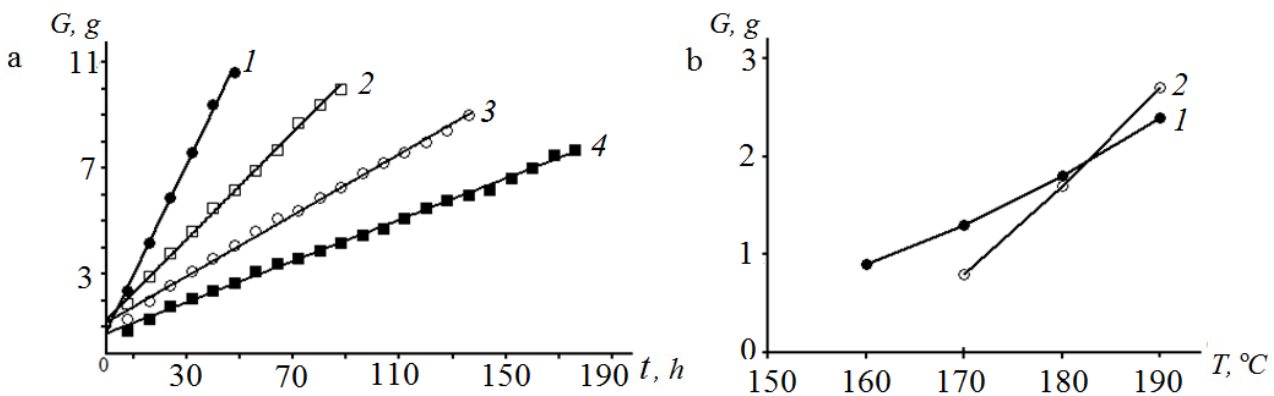

Fig. 4.(a)Dependence of volatility on time and testing temperature of synthetic motor oil ALPHA'S $5 \mathrm{~W}-30 \mathrm{SN} / \mathrm{GF}: 1-190{ }^{\circ} \mathrm{C}$; $2-180{ }^{\circ} \mathrm{C} ; 3-170{ }^{\circ} \mathrm{C} ; 4-160^{\circ} \mathrm{C}$; (b) Dependence of volatility on testing temperature of synthetic motor oils: 1 - ALPHA'S $5 \mathrm{~W}-$ 30 SN/GF; 2 - LUKoil Luxe 5W-30 SL/CF (testing time - 8 hours)

Second important operational factor of motor oil efficiency is critical temperature, which is determined by the time of evaporation of two grams of motor oil under different testing temperatures (Fig. 5).Regression equations of these dependence are described by a polynomial of the second degree

$$
\begin{array}{ll}
\text { ALPHA'S 5W-30 SN/GF } & t_{G}=0.0225 T^{2}-8.705 T+846.75 \\
\text { LUKoil Luxe 5W-30 SL/CF } & t_{G}=0.04875 T^{2}-18.367 T+1736.3
\end{array}
$$

Indexes of correlation are 0.999 and 0.996.

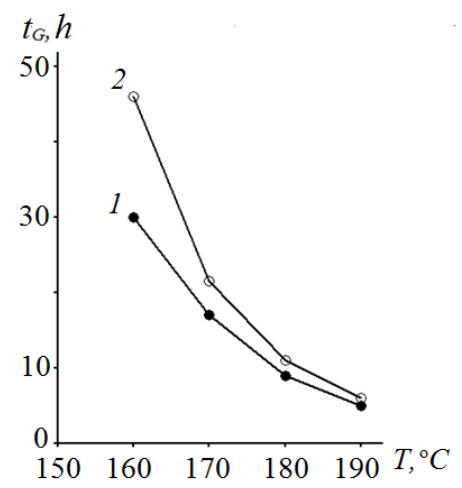

Fig. 5.Dependence of time required to evaporate two grams of synthetic oil on testing temperature:

$$
1 \text { - ALPHA'S 5W-30 SN/GF; } 2 \text { - LUKoil Luxe 5W-30 SL/CF }
$$

Derivatives of equations 13 and 14 determine the average rates of evaporation of two grams of oil from testing temperature. If we equate them to zero, it is possible to determine the onset temperatures of oxidation processes for oils under study. The results are $193.4^{\circ} \mathrm{C}$ for ALPHA'S 5W-30 SN/GF and $188.4^{\circ} \mathrm{C}$ for LUKoil Luxe 5W-30 SL/CF. 
Fig.6a shows dependence of coefficient of thermo-oxidative stability $P_{\text {tos }}$ on time and testing temperature of synthetic motor oil ALPHA'S 5W-30 SN/GF. These dependence are used to determine onset temperatures of oil conversion processes taking into account the processes of oxidation and evaporation, as well as the critical temperatures of their operability.
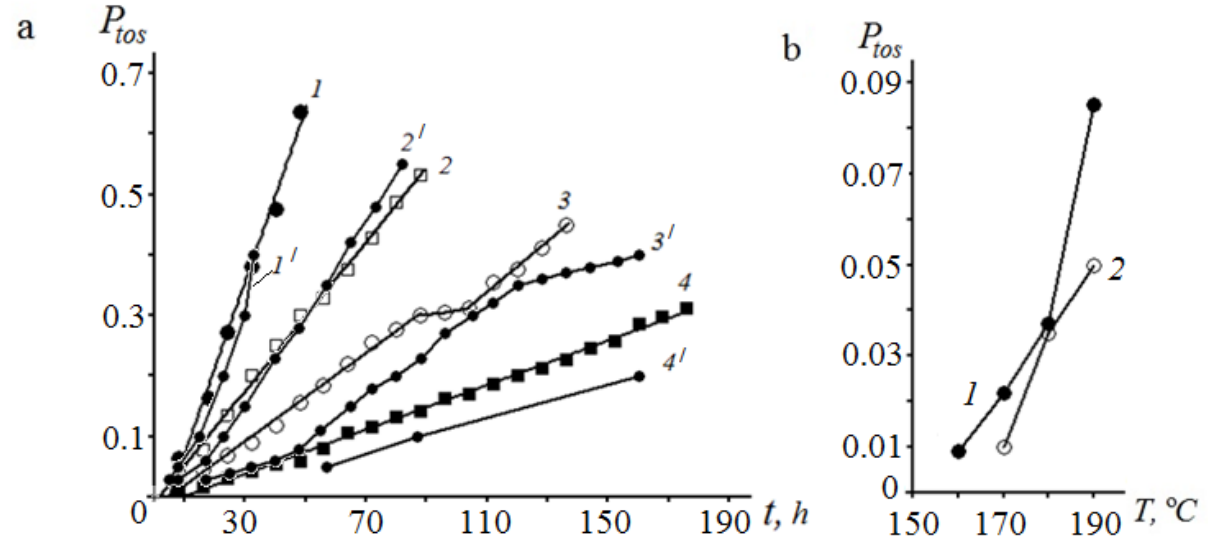

Fig. 6.(a)Dependence of thermo-oxidative index on time and testing temperature of synthetic motor oil ALPHA'S 5W-30 SN/GF: $1-190{ }^{\circ} \mathrm{C} ; 2-180{ }^{\circ} \mathrm{C} ; 3-170{ }^{\circ} \mathrm{C} ; 4-160{ }^{\circ} \mathrm{C}$ and LUKoil Luxe $5 \mathrm{~W}-30 \mathrm{SL} / \mathrm{CF}: 1^{\prime}-190{ }^{\circ} \mathrm{C} ; 2^{\prime}-180{ }^{\circ} \mathrm{C} ; 3^{\prime}-170^{\circ} \mathrm{C} ; 4^{\prime}-$ $160^{\circ} \mathrm{C}$; (b) Dependence of synthetic motor oils thermo-oxidation stability index on the test temperature: 1 - ALPHA'S 5W-30

SN/GF; 2 - LUKoil Luxe 5W-30 SL/CF (testing time - 8 hours)

Fig. $6 \mathrm{~b}$ shows the dependence of synthetic motor oils thermo-oxidation stability index on the test temperature after eight hours of testing. These dependences are described by a polynomial of the second degree, and regression equations for oils have the following form

$$
\begin{array}{ll}
\text { ALPHA'S 5W-30 SN/GF } & P_{\text {tos }}=\left(8 \times 10^{-5}\right) T^{2}-0.028195 T+2.28175 \\
\text { LUKoil Luxe 5W-30 SL/CF } & P_{\text {tos }}=\left(5 \times 10^{-5}\right) T^{2}-0.02 T-0.8
\end{array}
$$

Indexes of correlation are 0.985 and 1 .

Derivatives of equations 15 and 16 determine the average rates of conversion processes in oils under study. If we equate them to zero, it is possible to determine the onset temperatures of conversion processes. The results are $161.1^{\circ} \mathrm{C}$ for ALPHA'S 5W-30 SN/GF and $166.6^{\circ} \mathrm{C}$ for LUKoil Luxe $5 \mathrm{~W}-30 \mathrm{SL} / \mathrm{CF}$.

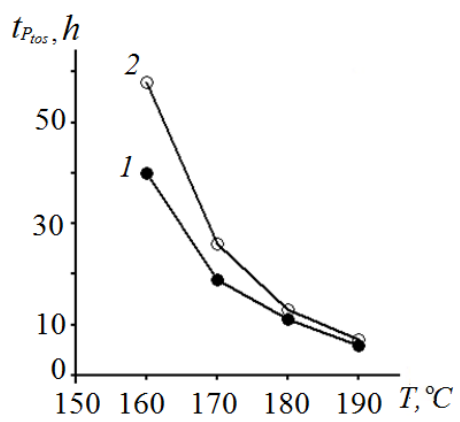

Fig. 7.Dependence of time required to achieve thermo-oxidation stability index $\mathrm{P}_{\text {tos }}=0.05$ on testing temperature of synthetic motor oils: 1 - ALPHA'S 5W-30 SN/GF; 2 - LUKoil Luxe 5W-30 SL/CF

Fig. 7 shows dependences of time required to achieve thermo-oxidation stability index $P_{\text {tos }}=0.05$ on testing temperature of synthetic motor oils. These dependences are described by a polynomial of the second degree, and regression equations for oils have the following form

$$
\begin{array}{cr}
\text { ALPHA'S 5W-30 SN/GF } & t_{P t o s}=0.04 T^{2}-15.1 T+1431.5 \\
\text { LUKoilLuxe 5W-30 SL/CF } & t_{P t o s}=0.065 T^{2}-0.02 T+0.8 \\
\text { Indexes of correlation are } 0.992 \text { and } 0.995 .
\end{array}
$$


Derivatives of equations 17 and 18 determine the rate of change of conversion time in synthetic oils on the testing temperature when index $P_{t o s}$ achieves value of 0.05 . If we equate them to zero, it is possible to determine the critical operability temperatures of synthetic motor oils under study. The results are $188.7^{\circ} \mathrm{C}$ for ALPHA'S $5 \mathrm{~W}-30 \mathrm{SN} / \mathrm{GF}$ and $187.7^{\circ} \mathrm{C}$ for LUKoil Luxe $5 \mathrm{~W}-30 \mathrm{SL} / \mathrm{CF}$. Thus, resistance to temperature conversions with a temperature drop to $160^{\circ} \mathrm{C}$ is higher in LUKoil Luxe $5 \mathrm{~W}-30 \mathrm{SL} / \mathrm{CF}$

\section{Conclusion}

The proposed control method of thermo-oxidative stability factors allows us to expand informationon the quality of lubricants by determining the onset temperatures of oxidation, evaporation and temperature conversions in oil, as well as critical temperatures of this processes. It also allows to improve the classification system by the groups of operational properties. The proposed grapho-analytical method for determining the parameters of thermo-oxidative stability makes it possible to reduce the labour inputs of the research more than twofold by using the results of the study obtained at two testing temperatures.

\section{References}

1. Kovalskiy BI, Derevyagina LN, Kirichenko IA (1996) Method of determining oxidative stability of lubricants. RF Patent 2,057,326, 27 Mar 1996

2. GOST $20457-75$. Oils. Method of evaluation of antioxidant properties on the installation of the IKM. 1977

3. GOST 11063-77. Oils with additives. Method of determining stability by the inductive period of sedimentation. 1979

4. GOST 18136-72. Oil. A method of determining the stability against oxidation in a universal device. 1974

5. Kowalski BI, Nazarov GG (1997) Photometric evaluation method for thermal oxidation stability of lubricants laboratory. Diagnostics of materials, vol 12, p 65

6. Ananin NN, Popov AS, Kowalski BI, Malysheva NN (2006) The Method of determining oxidative stability of lubricants, Youth and science - the third Millennium: Sat. materials of all-Russian scientific conference, Krasnoyarsk, p 346-349

7. Ananin NN, Danilenko VV, Kowalski BI, Malysheva NN (2006) Control Method for thermal oxidation stability of lubricants, Youth and science - the third Millennium: Sat. materials of all-Russian scientific conference, Part II, Krasnoyarsk, p 342-346

8. Kowalski BI, Malysheva NN, Musiyachenko EV, Bezborodov Yu. N, Metelitsa AA (2006) Thermal stability as a measure of quality lubricants, Vestnik KGTU: engineering, Krasnoyarsk, vol 41, p 7-17

9. Kowalski BI, Danilenko VS, Malysheva, NN, Bezborodov Yu N (2008) The method of determining oxidative stability of lubricants. RF Patent 2,318,206, 27 Feb 2008

10. Kovalsky BI, Vishnevskaya EA, Bezborodov YuN, Malysheva NN (2009) The method of determining oxidative stability of lubricants. RF Patent 2,371,706, 27 Oct 2009

11. Danilenko VS, Kowalski BI, Vishnevskaya EA, Malysheva NN, Bezborodov YuN (2009) Method of determining oxidative stability of lubricants, VestnikSibSAU, Krasnoyarsk, vol 1(22) , p 93-96

12. Kowalski BI, Bezborodov JN, Malysheva NN, Kravtsova EG (2012) Method of quality control of lubricating oils, the Collection of scientific works SWorld on materials of the international practical conference "Modern problems and ways of their solution in science, transport, production and education 2012", Odessa, Issue 4, vol 5, p 67-69

13. Kowalski BI, Kravtsova EG, Malysheva NN, Berko AV (2013) Control Method for thermal oxidation stability and thermal resistance, Journal Control. Diagnostics, Moscow, vol 13, p 113-116

14. Kowalski BI, Malysheva NN, Kravtsova EG, Shram VG (2013) System control of lubricants, Scientific-technological journal "Industrial service", Moscow, vol 2 (47), p 17-21

15. Kowalski BI, Kravtsova EG, Bezborodov YuN, Lysaya MA (2014) The Method of monitoring the effect of temperature on the oxidation of synthetic motor oils, Izvestiya of the Tula state University, Technical Sciences, Tula, vol 4, p 99-108

16. Kowalski BI, Kravtsova EG, Lysyannikova NN, Artemov MN (2015) Method of controlling the effects of oxidation and thermal degradation on the change of viscosity index of engine oils, Izvestiya of the Tula state University, Technical Sciences, Tula, vol 8-2, p109-115

17. Lysyannikova NN, Kovalski BI, Bezborodov YuN, Lysyannikov AV, Kravtsova YeG, Shram VG (2016) Control methods of operational properties of lubricants. IOP Conf. Ser. doi:10.1088/1757-899X/132/1/012026

18. Kowalski BI, Abazin DD, Vereshchagin VI, Lysyannikova NN (2017) Thermal and oxidation stability of synthetic motor oils, Izvestiya of the Tula state University, Technical Sciences, Tula, vol 6, p 200-210

19. Kowalski BI (2005) Methods and means of improving the effectiveness of use of lubricants. Monography, Novosibirsk

20. Kowalski BI, Bezborodov JN, Lysyannikova NN (2011) Controls lubricants for machines and mechanisms of varying degrees of loading, Krasnoyarsk, p 132

21. Malysheva NN, Kravtsov EG, Kowalski BI. (2014) Method for determining the quality of lubricating oils. RF Patent 2,528,083, 10 Sept 2014. 